EPiC Series in Engineering
Volume 3, 2018, Pages 2241-2249
HIC 2018. 13th International
Conference on Hydroinformatics

\title{
Integrated Model for Water, Food, Energy and Human Development
}

\author{
K N Waimbo ${ }^{1}$, D Savic ${ }^{1}$ and F A Memon ${ }^{1}$ \\ ${ }^{1}$ Centre for Water Systems, University of Exeter, Exeter, U.K. \\ kw387@exeter.ac.uk, D.Saviclexeter.ac.uk, F.A.Memon@exeter.ac.uk
}

\begin{abstract}
Water, food, and energy are basic needs crucial to human survival but also pervade many aspects of human development. Systemically, they are vastly interdependent. A system dynamics model comprises five modules, namely water, food, energy, demographic, and human development, is being constructed. The aim is to evaluate the dynamics behaviour of water, food, and energy systems and their linkages to human development at national scale. The model was simulated on annual basis from the year 1990 to 2015. It was then tested against national historical data of Indonesia. Analysis of error using mean-square error, root mean square percent error, and Theil inequality statistics were performed to test model behaviour. Preliminary results show that total population, income per capita, human development index, and sectoral water demands have root mean square percent error below $10 \%$ which indicate the model produces similar behaviour pattern to the actual system. As part of the future work, once the model is fully constructed, it will be applied to assess the impact of a range of policy scenarios and implications on the water, food, and energy sectors and on human development in Indonesia.
\end{abstract}

\section{Introduction}

Water, Food, and Energy (WFE) are basic needs crucial to human survival but also pervade many aspects of human development. Systemically, they are vastly interdependent, and hence an effort to secure one sector may destabilizes others (Bazilian et al., 2011; WWF, 2014). Therefore, it is important to understand the complex interactions among these sectors.

In this paper, we present a System Dynamics (SD) model of water, food, energy, and human development, or in short WFE-HD model. See (Sterman, 2000) for details on system dynamics modelling technique.

WFE-HD model is to be used for the following purposes:

- As a tool to evaluate the dynamics behaviours of WFE systems and their linkages to human development. 
- As a tool to assess better policies formation on securing water, food and energy and sustainably improving human development.

The model is generic, however, purposely develop to be implemented in Indonesia for the following reasons:

- The government of Indonesia has been actively pursuing sustainable development agendas. They have set development targets in water, food, and energy sectors to be achieved in 2019 (e.g., improving access to drinking water and sanitation to $100 \%$, rehabilitating 5.5 million ha of critical land in forest management units and priority watersheds, increasing electrification ratio to $96.6 \%$, reaching $10-16 \%$ of renewable energy share in the energy mix, increasing calorie intake to $2150 \mathrm{kCal}$, expanding agricultural land by $300,000 \mathrm{ha}$, and increasing production of rice, soy, sugar, and beef by $26 \%, 109 \%, 46 \%$, and $67 \%$, respectively (Bellfield, Sabogal, Pareira, Gangga, \& Leggett, 2017)). We plan to use this model to assess the impacts of these targets.

- The model may also be used to inform Indonesia policy makers the impact of a range of policy scenarios and implications on WFE security and human development, so they may be aware of such consequences when formulating the next 2020-2025 mediumdevelopment plan.

\section{Methods}

WFE-HD model was developed using SD modelling technique. The model was built and simulated using MATLAB/Simulink R2017a software. The model comprises five modules, namely demographic, human development, water sector, energy sector, and food sector. Figure 1 shows the model framework. The model was simulated in yearly basis from the year 1990 to 2015 . We used data from Indonesia to test model behaviour. The next subsections briefly describe model development.

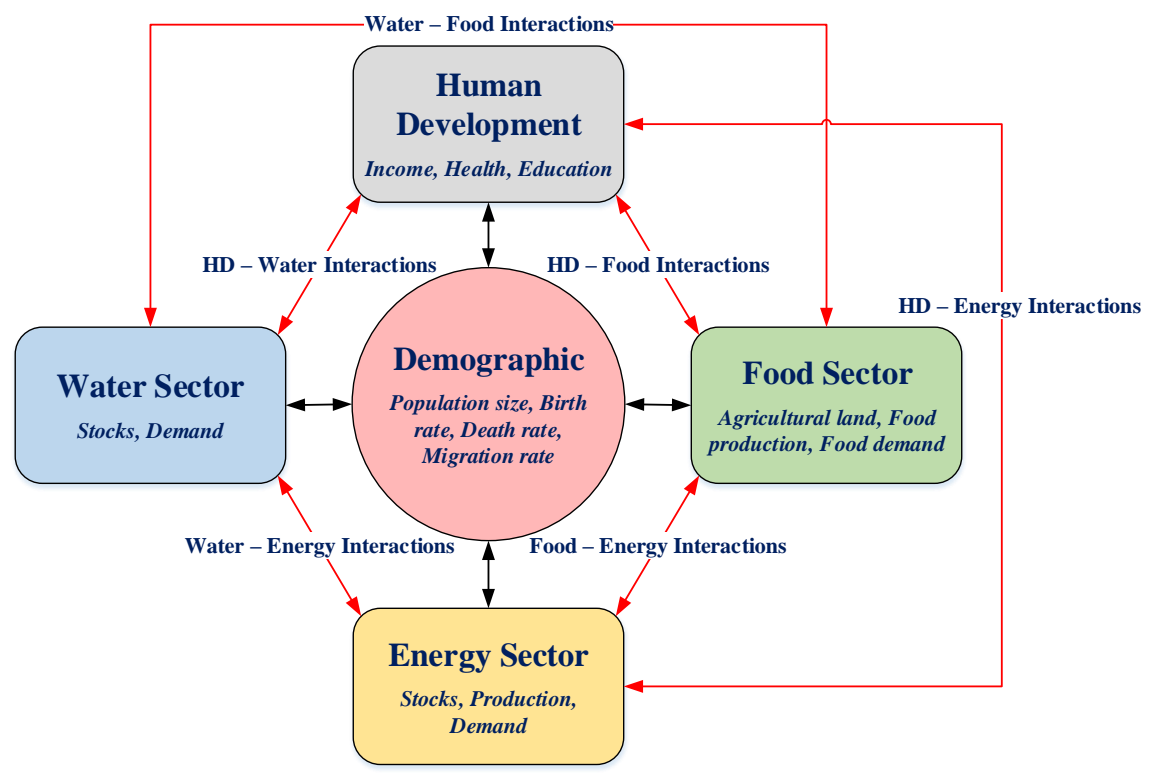

Figure 1: WFE-HD Model Framework 


\subsection{Demographic Module}

Demographic module was developed to model the dynamics of populations size. Population size is one of the key drivers of change in the system, e.g., it directly influences water, food, and energy consumptions. Our demographic model was adopted from the four-level age structure model of World 3 model (Meadows et al., 1974) with the following modifications:

- The model was built for national scale hence international migration was included in the model. The net migration rate was generated exogenously and linked to the working age group.

- Age levels were grouped according to Indonesia statistics criteria (BPS-Statistics Indonesia, 2017) in which the reproductive population is defined as people of the age 15 to 49 years old.

- Age specific mortality rate was defined as a linear function of life expectancy at birth according to the following formula (Lee \& Carter, 1992; Pascariu \& Canudas-Romo, 2015; Ševčíková, Li, Kantorová, Gerland, \& Raftery, 2016; Wilmoth, Zureick, Canudas-Romo, Inoue, \& Sawyer, 2012):

$$
M_{x}=a_{x} \cdot \mathrm{LE}+b_{x}
$$

where $M_{x}$ is age specific mortality rate [year $\left.{ }^{-1}\right] ; L E$ is life expectancy at birth; $a_{x}$ and $b_{x}$ are age-specific parameters [dmsl].

- Total fertility rate was defined as a function of income per capita using the following exponential model:

$$
T F R=a \cdot e^{b \cdot I n c o m e p c}+c \cdot e^{d \cdot I n c o m e p c}
$$

where TFR is Total Fertility Rate [dmsl]; $a, b, c, d$ are model parameters [dmsl]; Incomepc is income per capita [\$/person].

The inputs to demographic module are income per capita and life expectancy. Both are generated in human development module. Outputs from demographic module are total population and four-level age groups population size.

\subsection{Human Development Module}

The human development model was characterized by the Human Development Index (HDI), a composite index constructed by Mahbub ul Haq (Haq, 2003). HDI is calculated as function of life expectancy at birth, mean and expected years of schooling, and income per capita (HDRO, 2015b). In this module, life expectancy at birth and income per capita were generated endogenously, while mean and expected years of schooling were generated exogenously.

Income per capita was defined as national Gross Domestic Product (GDP) per total population. GDP was modelled as function of human capital or labour, capital stock, and energy production based on the LINEX production function after Kummel (Reiner Kiimmel, Strassl, Gossner, \& Eichhorn, 1985). LINEX function can be expressed mathematically as follow:

$$
G D P=q_{o} \cdot E \cdot e^{a_{0} \cdot\left(2-\frac{L+E}{K}\right)+a_{0} \cdot c_{t} \cdot\left(\frac{L}{E}-1\right)}
$$

where $\mathrm{E}$ is energy production [GWh], $\mathrm{L}$ is labour [person], $\mathrm{K}$ is capital stocks [\$], and $q_{o}, a_{o}, c_{t}$ are LINEX parameters.

Life expectancy at birth was modelled as function of income per capita that can be expressed mathematically as follow:

$$
L E=a_{t} \cdot \operatorname{Ln}(\text { Incomepc })+b_{t}
$$

where $a_{t}$ and $b_{t}$ are model parameters.

The inputs to the human development module are population size, food consumption, water consumption, and energy consumption. The outputs from human development module are income per capita and life expectancy at birth. 


\subsection{Water Sector Module}

Water sector module was constructed to model freshwater supply-demand balance on national scale. An earlier developed model (Akhtar, Wibe, Simonovic, \& MacGee, 2013; Alcamo et al., 2003; Rosegrant, 2012) has been tailored to facilitate its integration into our system model. Mathematical representations for the water sector model are as follow:

$$
\begin{aligned}
& T W S=S W S+G W S-T W U \\
& S W S=R W F \times \text { Runoff rate } \\
& G W S=R W F \times \text { Infiltration rate } \\
& R W F=\text { Rainfall } \times L A \\
& T W U=D W U+I W U+A W U \\
& D W U=D W \times \text { Total population } \\
& D W I=D S W \times\left(1-\eta_{d}\right)^{t-t_{0}} \\
& D S W I=D S W I_{\min }+D S W I_{\max } \times\left(1-e^{-\gamma_{d} \cdot \text { Incomepc }^{2}}\right) \\
& I W U=I W \times E P \\
& I W I=I S W \times\left(1-\eta_{i}\right)^{t-t_{0}} \\
& I S W I=I S W I_{\min }+\frac{1}{\gamma_{i} \cdot\left(\text { Incomepc } \text { Incomep }_{\text {Init }}\right)} \\
& A W U=\frac{I R_{n e t}}{\eta_{a}} \cdot I L A+\sum_{j}\left(365 \cdot \text { LWI }_{j} \cdot \text { LPOP }_{j}\right)
\end{aligned}
$$

where, $T W S$ is total water stock $\left[\mathrm{km}^{3}\right] ; S W S$ is surface water stock $\left[\mathrm{km}^{3}\right] ; G W S$ is ground water stock $\left[\mathrm{km}^{3}\right] ; R W F$ is rain water flowrate $\left[\mathrm{km}^{3} /\right.$ year]; $L A$ is land area $\left[\mathrm{km}^{2}\right]$; Rainfall $[\mathrm{mm} /$ year]; $T W U$ is total water use $\left[\mathrm{km}^{3} /\right.$ year]; $D W U$ is domestic water use $\left[\mathrm{km}^{3} /\right.$ year]; $I W U$ is industrial water use $\left[\mathrm{km}^{3} /\right.$ year]; $A W U$ is agricultural water use $\left[\mathrm{km}^{3} /\right.$ year]; $D W I$ is domestic water intensity $\left[\mathrm{km}^{3} /\right.$ person]; $D S W I$ is domestic structural water intensity $\left[\mathrm{km}^{3} /\right.$ person]; $\eta_{\mathrm{d}}$ is rate of improvement in the efficiency of domestic water use [\% year $\left.{ }^{-1}\right]$; IWI is industrial water intensity $\left[\mathrm{km}^{3} / \mathrm{MWh}\right] ; I S W I$ is industrial structural water intensity $\left[\mathrm{km}^{3} / \mathrm{MWh}\right] ; \eta_{\mathrm{i}}$ is rate of improvement in the efficiency of industrial water use [\% year $\left.{ }^{-1}\right] ; E P$ is electricity production [MWh]; IR net is net irrigation requirement [mm/year]; ILA is irrigated land area $\left[\mathrm{km}^{2}\right] ; \quad \eta_{\mathrm{a}}$ is agricultural irrigation efficiency; $L W I_{j}$ is water intensity per unit of livestock $j$ $\left[\mathrm{m}^{3} /\right.$ day/head]; and $L P O P_{j}$ is total population of livestock $j$ [head].

The inputs to the water sector module are total population, income per capita, energy production, irrigated land area, and selected livestock (i.e., cattle, buffalo, horse, sheep, goat, pig, and poultry). The outputs from water sector module are water stock and total water demand and sectoral water demands (i.e., domestic, industrial, and agricultural water demand).

\subsection{Modules Integration}

Modules for food sector and energy sector are being developed hence not presented here. Once each module has been fully developed, they will be integrated as a system model as shown schematically in Figure 1. 


\subsection{Model Testing}

Model testing is aimed to increase the confidence in the SD model to the extent that the dynamic behaviour of the real system can be explained or assessed by the model. Model tests relate to model structure, model behaviour, and model's policy implications (Barlas, 1989; Forrester \& Senge, 1980). We only present test of model behaviour in this paper.

We used mean square error (MSE) (equation (17)) or root mean square percent error (RMSPE) (equation (18)) to test model behaviour against historical data. Furthermore, to identify the types and sources of error, total error or MSE is decomposed using Theil inequality statistics (equation (19) to (21)) (see (Sterman, 1984) for details explanation).

$$
\begin{aligned}
M S E=\frac{1}{n} \sum\left(X_{S}-X_{A}\right)^{2} & U^{M}=\frac{\left(\overline{X_{S}}-\overline{X_{A}}\right)^{2}}{M S E} \\
R M S P E=100 \times \sqrt{\frac{1}{n} \sum\left(\frac{X_{S}-X_{A}}{X_{A}}\right)^{2}}(18) & U^{S}=\frac{\left(S_{S}-S_{A}\right)^{2}}{M S E} \\
U^{C} & =\frac{2(1-r) \cdot S_{S} \cdot S_{A}}{M S E}
\end{aligned}
$$

where, ${ }_{s}$ and ${ }_{A}$ represent simulated and actual data; $X$ is component value; $n$ is the length of data; Xbar is mean value; $S$ is standard deviation; $r$ is correlation coefficient of simulated and actual data; $U^{M}$ is the fraction of MSE due to bias; $U^{S}$ is fraction of MSE due to the unequal variance; $U^{C}$ is the fraction of MSE due to unequal covariance.

The model passes behaviour test if one of these two conditions is met:

- $\mathrm{RMSPE}<10 \%$.

- $U^{C}>50 \%$ or $U^{M}+U^{S}<50 \%$

\subsection{Data}

Data for model testing were collected from several sources e.g., data for population size were taken from Indonesia Statistics (BPS-Statistics Indonesia, 2016) and UN data; data for human development index were taken from United Nation Human Development Report (UN HDR) (HDRO, 2015a); data for GDP and GDP per capita were taken from World Bank (The World Bank, 2017), data for sectoral water use were taken from Indonesia Statistics and FAO (FAO, 2015); and data for electricity production were taken from British Petroleum (BP) Statistical Review of World Energy (BP, 2017).

\section{Preliminary Results and Discussion}

Figure 2 shows preliminary results of the model outputs for demographic (Figure 2(a)), human development (Figure 2(b-c)), and water sector module (Figure 2(d-e)) plotted along with the historical or reference data. The corresponding results for the model behavioural test are given in Table 1.

The outputs from demographic module show good agreement with the historical and reference data. Inequality error analysis show that the error in this module model is not systematic, i.e., the error due to bias and unequal variance is below 50\%. Output from human development module also shows good agreement as indicated by RMSPE below $10 \%$ (i.e., HDI $0.60 \%$ and GDP per capita $7.08 \%$ ). However, the error in GDP per capita could be systematic because the error due to bias $\left(U^{M}\right)$ is $60.8 \%$, which is above the passing criteria. The potential cause of this error could be the difference in LINEX parameters we used. On the water sector module, due to limited available data, we tested the result for domestic and industrial water use separate from the agricultural water use. Results for the water domestic and 
industrial water use show good agreement with data from Indonesian statistic for the period 2010 to 2015 as shown in Figure 2(d). The agricultural water use on the other hand has only two data points that we obtained from FAO, which are data for the year 1990 and 2000. We assumed linear increase of agricultural water use in-between period 1999 to 2000 then used it as reference data. Test result shows that the model produce similar linear pattern to the reference data

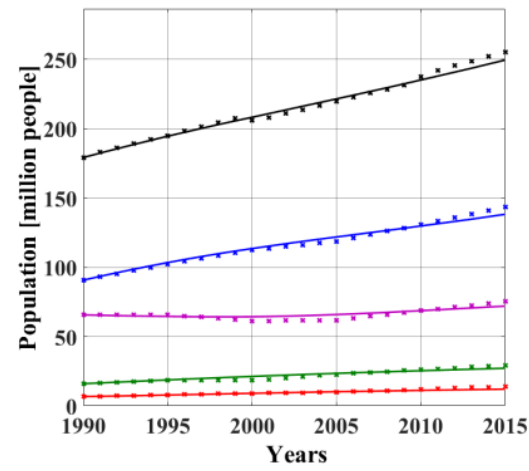

* Total [UN]

- Total [Simulation]

* P1 [UN]

-P1 [Simulation]

* P2 [UN]

- P2 [Simulation]

-P3 [Sim

* P4 [UN]

- P4 [Simulation]

$\mathrm{P} 1$ is population age $0-14$

$\mathrm{P} 2$ is population age $15-49$

$\mathrm{P} 3$ is population age 50-64

$\mathrm{P} 4$ is population age $65+$

(a)

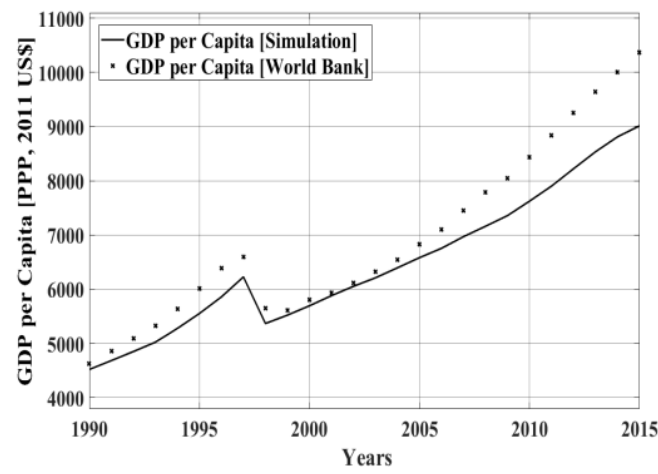

(b)

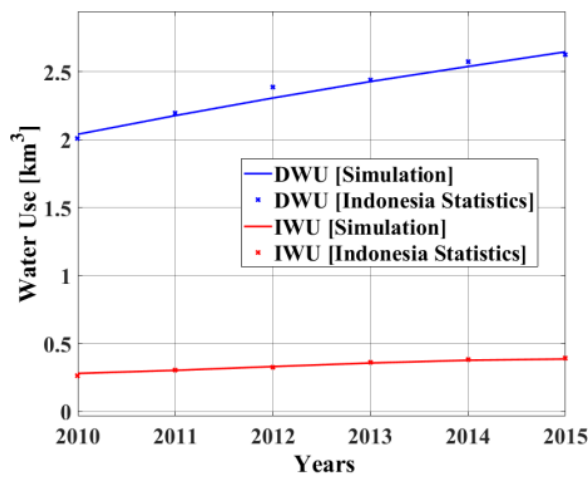

(d)

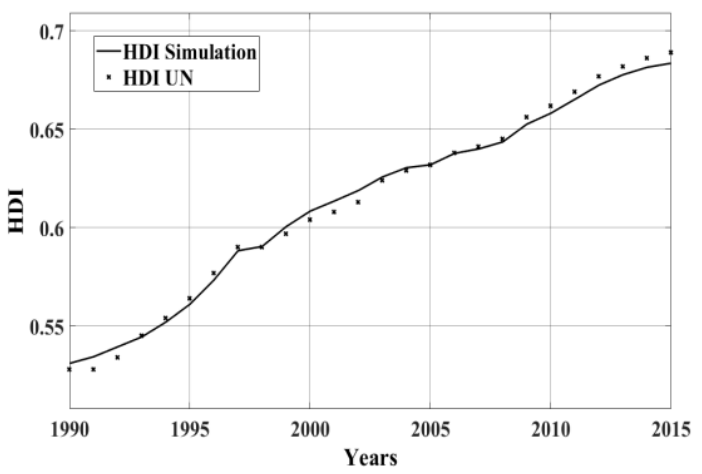

(c)

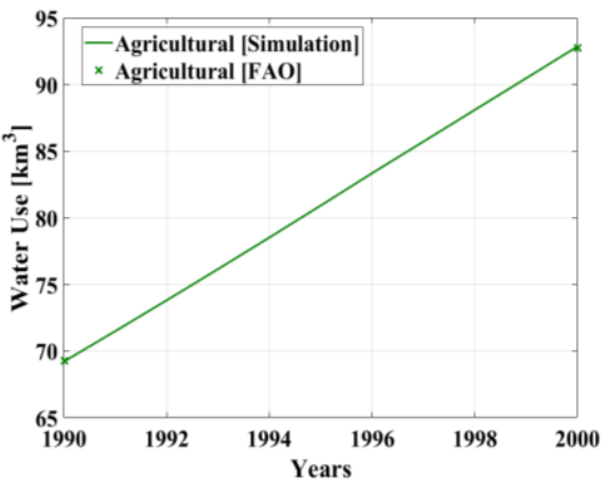

(e)

Figure 2 Simulation results for demographic module, human development module, and water sector module: (a) population, (b) income per capita, (c) HDI, (d) domestic and industrial water use, (e) 


\begin{tabular}{|l|c|c|c|c|c|}
\hline \multirow{2}{*}{ Variable } & \multirow{2}{*}{$\begin{array}{c}\text { RMSPE } \\
{[\%]}\end{array}$} & \multirow{2}{*}{$\begin{array}{c}\text { MSE } \\
{\left[\text { units }^{2}\right]}\end{array}$} & \multicolumn{3}{|c|}{$\begin{array}{c}\text { Theil Inequality Statistics } \\
\text { (fraction of total error) }\end{array}$} \\
\cline { 4 - 6 } & & & $\mathrm{U}^{\mathrm{M}}$ & $\mathrm{U}^{\mathrm{S}}$ & $\mathrm{U}^{\mathrm{C}}$ \\
\hline Total population [million people] & 1.11 & 7.00 & 0.057 & 0.230 & 0.712 \\
\hline Population age 0-14 [million people] & 3.38 & 4.70 & 0.096 & 0.491 & 0.413 \\
\hline Population age 15-49 [million people] & 1.72 & 4.76 & 0.024 & 0.347 & 0.629 \\
\hline Population age 50-64 [million people] & 6.65 & 1.89 & 0.076 & 0.319 & 0.605 \\
\hline Population age 64+ [million people] & 5.45 & 0.49 & 0.286 & 0.369 & 0.345 \\
\hline GDP per capita [PPP, 2011 US\$] & 7.08 & $3.63 \times 10^{5}$ & 0.608 & 0.319 & 0.073 \\
\hline HDI [dmsl] & 0.60 & $1.34 \times 10^{-5}$ & 0.004 & 0.336 & 0.660 \\
\hline Domestic water use $\left[\mathrm{km}^{3}\right]$ & 1.68 & 0.0016 & 0.149 & 0.024 & 0.827 \\
\hline Industrial water use $\left[\mathrm{km}^{3}\right]$ & 2.98 & $7.18 \times 10^{-5}$ & 0.009 & 0.777 & 0.214 \\
\hline Agricultural water use $\left[\mathrm{km}^{3}\right.$ ] & 0.11 & 0.008 & 0.203 & 0.473 & 0.324 \\
\hline
\end{tabular}

Table 1: Model Error Analysis

\section{Conclusions and Future Works}

An integrated model comprising water, food, energy, demographic and human development module is being constructed. The model is developed using system dynamics modelling approach. Out of five modules, three have been built, namely demographic, human development and water sector. Preliminary results show that the total error for most of the model variables that were endogenously generated are below ten percent which indicate our model generated similar behaviour to the real system. However, further works is still needed to be done especially obtaining enough reference data for model calibration and validation.

Future works include developing food and energy module. Once each module has been developed and tested, they will be integrated. We will carry out sensitivity and uncertainty analysis for the model parameters. We will also use the model to evaluate different policy scenarios to support decision making for the development of WFE to improve human development in Indonesia. Furthermore, our model is a generic model hence it can be implemented in different country with proper calibration.

\section{Acknowledgments}

The government of Indonesia through Indonesia Endowment Fund for Education scheme funded this work. The authors thanking Indonesia government for financial support.

\section{References}

Akhtar, M. K., Wibe, J., Simonovic, S. P., \& MacGee, J. (2013). Integrated assessment model of society-biosphere-climate-economy-energy system. Environmental Modelling \& Software, 49, $1-21$.

Alcamo, J., Doll, P., Henrichs, T., Kaspar, F., Lehner, B., Rosch, T., \& Siebert, S. (2003). Development and testing of the WaterGAP 2 global model of water use and availability. Hydrological Sciences Journal, 48(3), 317-337. 
Barlas, Y. (1989). Multiple tests for validation of system dynamics type of simulation models. European Journal of Operational Research, 42(1), 59-87.

Bazilian, M., Rogner, H., Howells, M., Hermann, S., Arent, D., Gielen, D., ... Yumkella, K. K. (2011). Considering the energy, water and food nexus: Towards an integrated modelling approach. Energy Policy, 39(12), 7896-7906.

Bellfield, H., Sabogal, D., Pareira, J., Gangga, A., \& Leggett, M. (2017). Achieving Water, Energy and Food Security in Indonesia.

BP. (2017). BP Statistical Review of World Energy 2017.

BPS-Statistics Indonesia. (2016). Statistical Yearbook of Indonesia 2016. Jakarta.

BPS-Statistics Indonesia. (2017). Glossary. Retrieved May 24, 2017, from https://www.bps.go.id/istilah

FAO. (2015). AQUASTAT. Food and Agriculture Organization of the United Nations. Retrieved May 24, 2016, from http://www.fao.org/nr/water/aquastat/water_use/index.stm

Forrester, J. W., \& Senge, P. M. (1980). Test for Building Confidence in System Dynamics Models. TIMS Studies in the Management Sciences, 14, 209-228.

Haq, M. ul. (2003). The Birth of The Human Development Index. In S. Fukuda-Parr \& A. K. S. Kuma (Eds.), Reading in Human Development (pp. 127-137). Oxford: Oxford University Press.

HDRO. (2015a). Human Development Data (1990-2015) | Human Development Reports. Retrieved May 20, 2017, from http://hdr.undp.org/en/data

HDRO. (2015b). Technical notes. Human Development Report 2015 Work for Human Development. New York.

Lee, R. D., \& Carter, L. R. (1992). Modeling and Forecasting U. S. Mortality. Journal of the American Statistical Association, 87(419), 659.

Meadows, D. L., William W. Behrens, I., Meadows, D. H., Naill, R. F., Randers, J., \& Zahn, E. K. O. (1974). Dynamics of Growth in A Finite World. Cambridge: Wright-Allen Press, Inc.

Pascariu, M., \& Canudas-Romo, V. (2015). Deriving age-specific death rates from life expectancy forecasts.

Reiner Kiimmel, B., Strassl, W., Gossner, A., \& Eichhorn, W. (1985). Technical Progress and Energy Dependent Production Functions*, 45(3), 285-311.

Rosegrant, M. W. (2012). International Model for Policy Analysis of Agricultural Commodities and Trade (IMPACT): Model Description. Washington, D.C.

Ševčíková, H., Li, N., Kantorová, V., Gerland, P., \& Raftery, A. E. (2016). Age-Specific Mortality and Fertility Rates for Probabilistic Population Projections (pp. 285-310). Springer, Cham.

Sterman, J. D. (1984). Appropriate summary statistics for evaluating the historical fit of system dynamics models. Dynamica.

Sterman, J. D. (2000). Business dynamics: systems thinking and modeling for a complex world. Boston: Irwin McGraw-Hill.

The World Bank. (2017). GDP per capita (current US\$)|Data. Retrieved May 20, 2017, from http://data.worldbank.org/indicator/NY.GDP.PCAP.CD 
Wilmoth, J., Zureick, S., Canudas-Romo, V., Inoue, M., \& Sawyer, C. (2012). A flexible twodimensional mortality model for use in indirect estimation. Population Studies, 66(1), 1-28.

WWF. (2014). Living Planet Report 2014. Gland, Switzerland. 